\title{
Influence of the Mechanical Loading History on the Stress Assisted Two Way Memory Effect in a Ti-Ni-Cu Alloy
}

\author{
Carlos José de Araújo *a , Cézar Henrique Gonzalez***b, Michel Morin ${ }^{\mathrm{b}}$, \\ Gérard Guénin ${ }^{\mathrm{b}}$ \\ ${ }^{a}$ Departamento de Engenharia Mecânica, UFPB/Campus II, C.P. 10069, \\ Campina Grande - PB, Brazil \\ ${ }^{\mathrm{b}}$ Groupe d'Etude de Metallurgie Physique et Physique des Matériaux, INSA de Lyon, \\ 20, Avenue Albelt Einstein 6920, Villeurbanne, France
}

Received: November 21, 2000; Revised: June 27, 2001

\begin{abstract}
In this work, several tests of thermal cycling under constant load are carried out on Ti-45.0Ni$5.0 \mathrm{Cu}(\mathrm{at} \%)$ shape memory wires. The properties related to the Stress Assisted Two Way Memory Effect (SATWME) of the material are investigated as a function of the mechanical loading history for the same temperature range during cooling and heating. For this reason, two thermomechanical tests have been employed: tests I, where one sample is used for just one constant stress level test and tests II, where only one sample is employed for several constant stress level tests in sequence. The results obtained show that for loads applied below $150 \mathrm{MPa}$, the transformation temperatures and the thermal hysteresis associated with the transformation of the material are the same during the two tests. However, above $150 \mathrm{MPa}$ in tests II transformation temperatures and thermal hysteresis are respectively higher and smaller than the ones obtained in tests I. On the other hand, transformation temperatures obtained from both tests are in good agreement with the ones measured by DSC and electrical resistance measurements. It is also observed that the SATWME obtained by tests II is smaller than the one measured during tests I. It is shown that these different behaviors are induced by accumulation of plastic strain in the sample during tests II.
\end{abstract}

Keywords: shape memory alloys, martensitic transformation, two way memory effect, Ti-Ni alloy, plastic strain

\section{Introduction}

Shape memory alloys (SMA's), classified as "smart" metallic materials, are sensitive to temperature and/or stress producing a large macroscopic strain as a result of a thermoelastic martensitic transformation ${ }^{1,2}$. Among all SMA's, it is well accepted that Ti-Ni based alloys present the best shape memory properties and benefit by an excellent biocompatibility useful for many applications ${ }^{2}$. In addition, among the Ti-Ni systems, Ti-Ni-Cu alloys are very attractive showing very good thermomechanical properties ${ }^{3,4}$. It is important to notice that in these SMA's the $\mathrm{Cu}$ replaces the $\mathrm{Ni}$ and that below $5 \% \mathrm{Cu}$ (\%at) the $\mathrm{Ti}-\mathrm{Ni}-\mathrm{Cu}$ alloy presents the same martensitic transformation found in the equiatomic Ti-Ni alloy: B2 austenite (bcc) $\leftrightarrow$ monoclinic martensite ${ }^{4}$. The peculiar quasi-reversible thermomechanical properties presented by these alloys, like shape memory effect (SME) and superelasticity, are mainly influenced by

*e-mail: carlos@dem.ufpb.br

**CNPq researcher $-\mathrm{PhD}$ candidate

Trabalho apresentado no $14^{\circ}$ CBECIMAT, Águas de São Pedro, Dezembro de 2000 . some factors as chemical composition, amount of coldwork and heat treatment after cold-work ${ }^{2}$. In some Ti-Ni binary compositions, a combination of these factors can cause the presence of an intermediate phase between the austenite and martensite, called rhomboedral (R)-phase ${ }^{5}$. So, SMA's properties are strongly dependent upon thermomechanical history. For example, cold-work performed on a recrystallized material improves the mechanical properties of the alloy, and decreases the transformation temperatures, i.e., a highly cold-worked wire is slightly "colder" than a less cold-worked wire. A cold-worked material needs to be heat treated before it can exhibit superelastic or shape memory properties ${ }^{2}$.

The martensitic transformation of $\mathrm{Ti}-\mathrm{Ni}$ based alloys were well studied as a function of some typical thermomechanical treatments including solution treatment, annealing after cold working and aging after solution 
treatment ${ }^{6-9}$. In some cases, Ti-Ni alloys are cold worked in martensitic state. After this procedure, the plastically deformed martensite shows a complex structure including dislocations, vacancies and stabilized martensite variants ${ }^{8-}$ ${ }^{10}$. These defects are responsible for a total or partial stabilization of martensite variants causing a reduction of the transformed fraction during the heating of the material. As a consequence, a reduction of the heat of transformation as well as a decrease of the transformation temperatures (in relation to recrystallized state) after the first heating corresponding to the reverse transformation are observed ${ }^{11,12}$. Additionally, it has been confirmed that recrystallized stress-free Ti-Ni specimens submitted to thermal cycling also exhibit a reduction of the heat of transformation ${ }^{7,13}$ and a decrease of the martensitic transformation start temperature $\left(\mathrm{M}_{\mathrm{S}}\right)^{6,7}$, as a result of the introduction of dislocations. Despite SMA sensitivity to its thermomechanical history, some authors ${ }^{14}$ frequently use the same sample to assess SMA properties thus overlapping the effect of different thermomechanical loadings. The effect of this overlapping procedure on the thermomechanical properties of the SMA's is not yet well established and certainly can lead to some errors when it is used. So, the major aim of this work is to clarify the influence of the mechanical loading way on the shape memory properties of a Ti- $45.0 \mathrm{Ni}-5.0 \mathrm{Cu}$ (at $\%$ ) alloy by employing two different thermomechanical procedures: tests I, where different samples are used for just one constant stress level (without overlapping) and tests II, where only one sample is employed for different constant stress level (with overlapping). Tests I will be considered the reference to establish the role of the overlapping procedure followed during tests II.

\section{Experimental}

The specimens were commercial $\mathrm{Ti}-45.0 \mathrm{Ni}-5.0 \mathrm{Cu}$ (at\%) wires ( $0.55 \mathrm{~mm}$ in diameter) after cold drawing of about $40 \%$. As received material was submitted to a heat treatment at $425{ }^{\circ} \mathrm{C}$ for $1 \mathrm{~h}$ followed by cooling to room temperature. Figure 1 shows the electrical resistance (ER) curves corresponding to the martensitic transformation of the as-received (AR) and heat-treated (HT) materials. It is clear that cold drawing in AR wires suppress the martensitic tranformation and that low temperature annealing releases the transformation. Transformation temperatures of the HT specimens, as measured by a tangent method, are also shown in Fig. 1. The results pointed out in Fig. 1 were supported by DSC measurements (Mettler TA 3000). In Fig. 2 the mechanical properties of the AR and HT wires at $10{ }^{\circ} \mathrm{C}$ are compared, the last in the martensitic state. The stress $(\sigma) v s$. strain $(\varepsilon)$ curve of the AR material is typical of work-hardened Ti-Ni based specimens while the one corresponding to the $\mathrm{HT}$ wires present a small stress plateau starting at about $115 \mathrm{MPa}$, typically associated to the reori- entation of martensite variants under stress. The end of this plateau corresponds to $150 \mathrm{MPa}$.

The strain and ER change of the Ti-Ni-Cu wires were measured at the same time as a function of temperature during cooling and heating under constant load. For this reason, the four-terminal DC method was adapted on an apparatus presented in a previous paper ${ }^{15}$ and originally designed for fatigue tests in thermal cycling mode. A stable power supply is used to maintain a constant low intensity electrical current through the specimen wire. So, as the current is always constant, the ER change is proportional to the voltage signal (U) change of the specimen. The temperature of the wire specimens kept into a thermocontrolled silicone oil bath was monitored. As the experimental apparatus uses cylindrical grips ${ }^{15}$, load was applied in martensite to assure that the specimen wire remains straight during the first heating. Therefore, specimens with a gauge length between 25 and $30 \mathrm{~mm}$, were placed at $10{ }^{\circ} \mathrm{C}$ (martensitic state), loaded and then heated to $154^{\circ} \mathrm{C}$. It is clear that during cooling, martensite could profitably grow already oriented by the applied load. The strain was measured using a differential LVDT displacement sensor. A data acquisition system stores the LVDT and the voltage signals at $154{ }^{\circ} \mathrm{C}$ as reference and a computational program calcu-

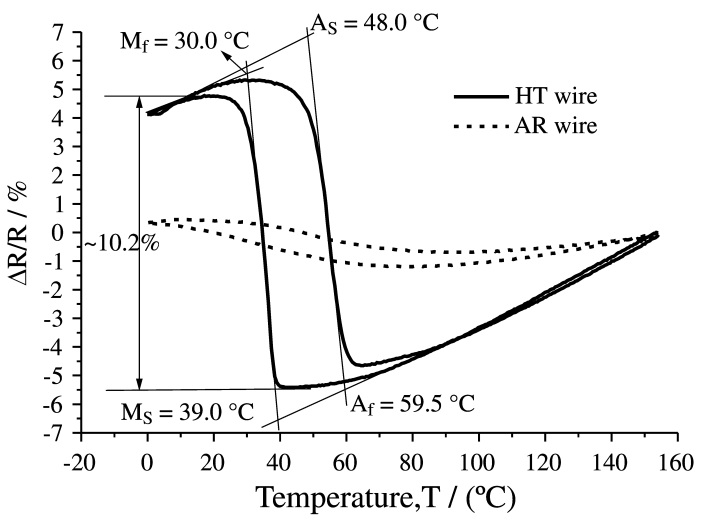

Figure 1. $\Delta \mathrm{R} / \mathrm{R}$ vs. $\mathrm{T}$ of the as-received (AR) and heat-treated (HT) Ti-Ni-Cu wires.

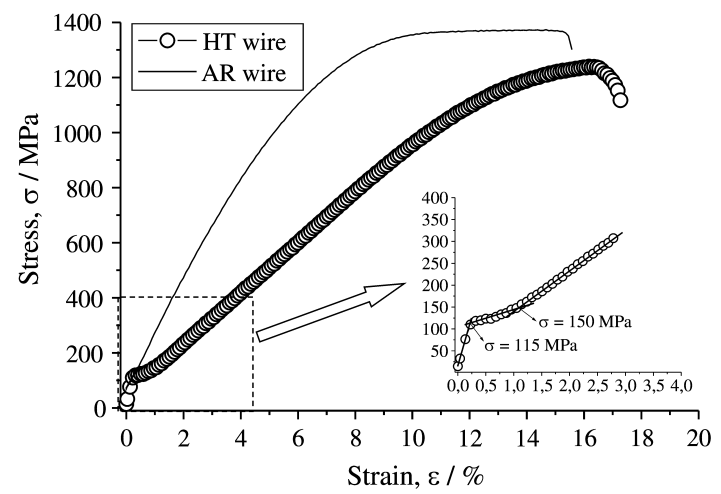

Figure 2. Stress-Strain curves of the as-received (AR) and heat-treated (HT) Ti-Ni-Cu shape memory wires at $10{ }^{\circ} \mathrm{C}$. 
lates the strains $(\varepsilon)$ and ER changes $(\Delta R / R)$ under load as a function of the temperature $(\mathrm{T})$ as follow:

$$
\begin{aligned}
& \varepsilon(T)=\frac{L V D T(T)-L V D T\left(154^{\circ} \mathrm{C}\right)}{\text { gauge_lenght }} \times 100(\%) \\
& \frac{\Delta R}{R}(T)=\frac{U(T)-U\left(154^{\circ} \mathrm{C}\right)}{U\left(154^{\circ} \mathrm{C}\right)} \times 100(\%)
\end{aligned}
$$

where LVDT(T) and $\mathrm{U}(\mathrm{T})$ are the displacement and voltage signals, respectively.

Constant applied stresses were set between 75 and $350 \mathrm{MPa}$. For all stress levels, temperature cycles were carried out between $10{ }^{\circ} \mathrm{C}$ and $154^{\circ} \mathrm{C}$. Several HT specimens were submitted to two kinds of thermomechanical tests:

- Tests I: different samples are used for each test at constant stress level;

- Tests II: only one sample is employed for several tests at constant stress level.

In the case of tests I, a cooling-heating-cooling cycle is performed in each HT specimen for each load applied. On the other hand, for tests II strain $(\varepsilon)$-ER-Temperature (T) measurements under various constant loads were carried out on the same specimen in the stress range 50-350 MPa, in steps of $25 \mathrm{MPa}$. For each stress level, the specimen was submitted to a cooling-heating-cooling cycle and the plastic strain introduced by this procedure was measured and added to the previous length of the specimen after each cycle.

In all cases, the ER measurements include a contribution due to strain, considering no volume changes during martensitic transformation under constant load. In fact, this assumption leads to a Poisson's coefficient of 0.5 in the generalized Ohm law for metallic conductors. So, the electrical resistivity variation can be obtained by the formula:

$$
\frac{\Delta \rho}{\rho}(T)=\frac{\Delta R}{R}(T)-2 \cdot \varepsilon(T)
$$

where $\Delta R / R(T)$ is the variation of ER and $\varepsilon(T)$ is the deformation during cycling obtained from Eqs. (1) and (2). Similar considerations were made by other authors ${ }^{16}$ studying Ti-Ni based SMA's.

\section{Results and Discussion}

As a result of the tests I and II, several curves corresponding to the $\varepsilon-\mathrm{T}, \Delta \mathrm{R} / \mathrm{R}-\mathrm{T}$ and $\Delta \rho / \rho-\mathrm{T}$ behaviors are
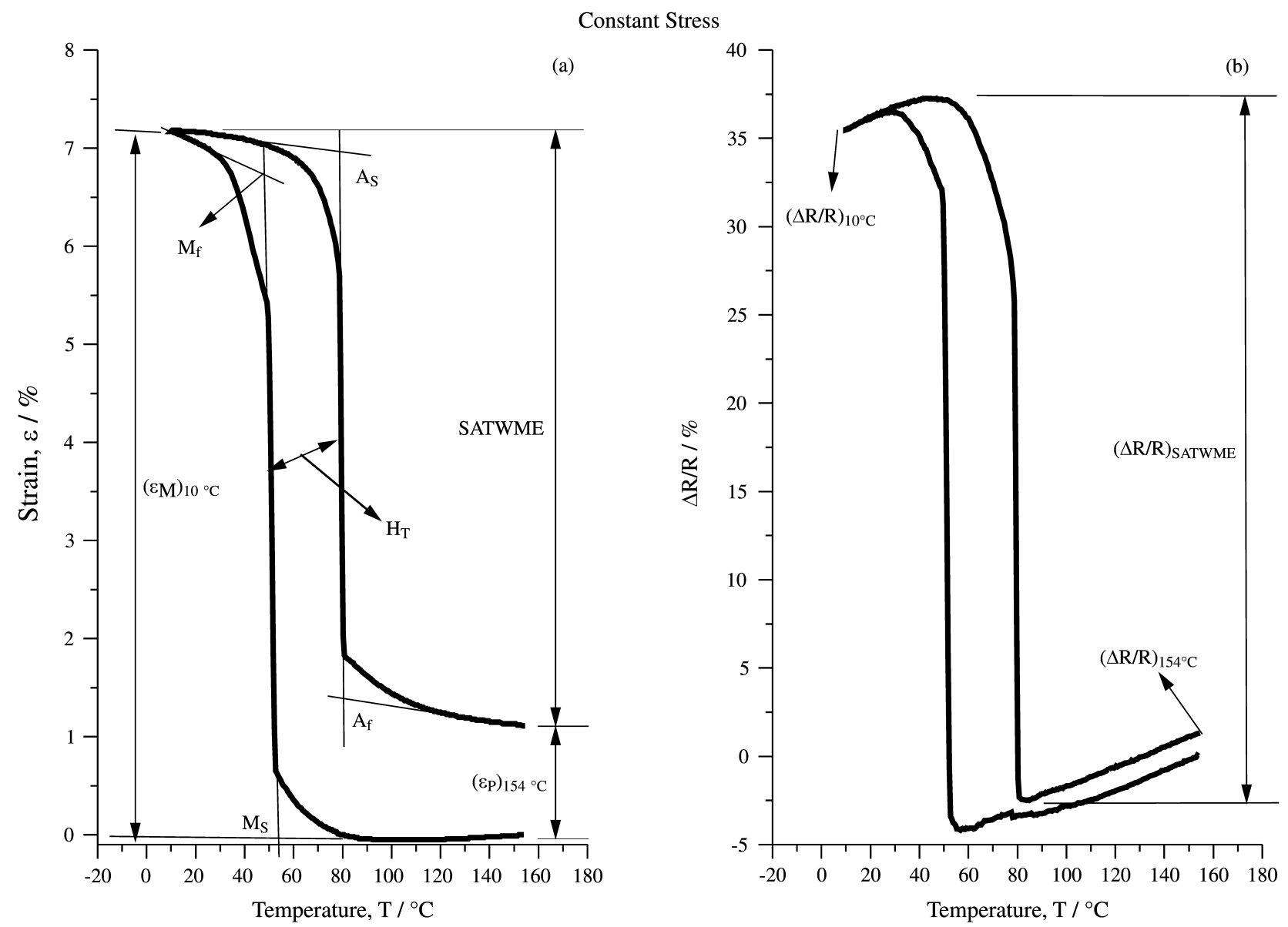

Figure 3. Representation of the (a) strain and (b) ER loops obtained during a typical test. The investigated parameters are pointed out on this figure. 
obtained. Typical $\varepsilon$-T and $\Delta \mathrm{R} / \mathrm{R}-\mathrm{T}$ loops are plotted in Fig. 3 and the chief deduced shape memory parameters are indicated. The measured strains are pointed out in Fig. 3(a): the low temperature strain $\left(\varepsilon_{\mathrm{M}}\right) 10^{\circ} \mathrm{C}$, the high temperature strain $\left(\varepsilon_{\mathrm{P}}\right)_{154}{ }^{\circ} \mathrm{C}$ and the stress assisted two-way memory effect (SATWME). $\left(\varepsilon_{\mathrm{M}}\right)_{10}{ }^{\circ} \mathrm{C}$ is the transformation strain associated with the orientation of martensite variants by the applied stress and $\left(\varepsilon_{\mathrm{P}}\right)_{154}{ }^{\circ} \mathrm{C}$ is the plastic strain under load after heating. It is clear from the Fig. 3(a) that the SATWME is calculated as the difference between $\left(\varepsilon_{\mathrm{M}}\right)_{10}{ }^{\circ} \mathrm{C}$ and $\left(\varepsilon_{\mathrm{P}}\right)_{154}{ }^{\circ} \mathrm{C}$. The transformation temperatures under cooling $\left(\mathrm{M}_{\mathrm{S}}\right.$ and $\mathrm{M}_{\mathrm{f}}$ ) or heating ( $\mathrm{A}_{\mathrm{S}}$ and $\mathrm{A}_{\mathrm{f}}$ ) can be measured using the tangent method as illustrated in Figs. 1 and 3(a). The variation of ER associated to the SATWME, $(\Delta R / R)_{\text {SAT- }}$ wME, as well as the ones at $10{ }^{\circ} \mathrm{C}$ and $154{ }^{\circ} \mathrm{C}$ are measured as defined in Fig. 3(b). The $\Delta \rho / \rho-\mathrm{T}$ curve is not plotted in Fig. 3, however it is easily obtained by applying Eq. (3) on the data corresponding to the Figs. 3(a) and 3(b).

\subsection{Strain evolutions}

The behavior of the strains and SATWME as a function of the applied stress for both kind of employed test is pointed out respectively in Figs. 4(a) and 4(b). From the

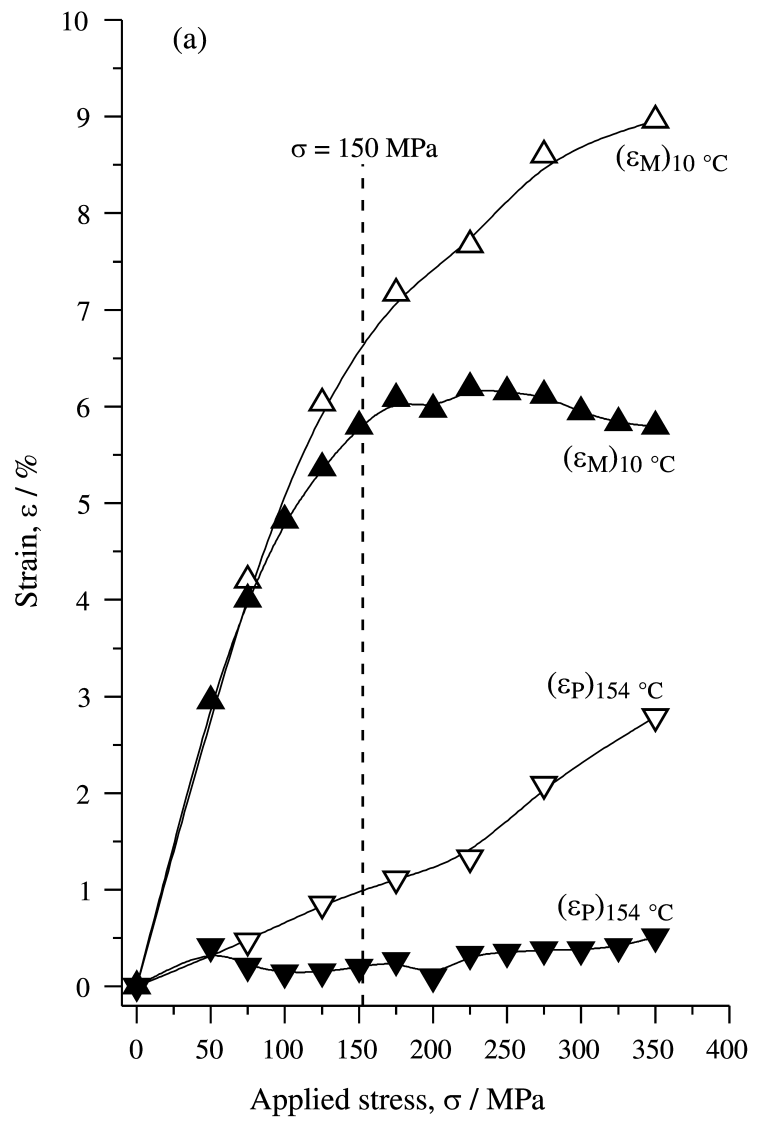

Fig. 4(a), it is clear that $\left(\varepsilon_{\mathrm{M}}\right)_{10{ }^{\circ} \mathrm{C}}$ and $\left(\varepsilon_{\mathrm{P}}\right)_{154}{ }^{\circ} \mathrm{C}$ reach higher values during tests I than during tests II. During tests II, $\left(\varepsilon_{\mathrm{P}}\right) 154{ }^{\circ} \mathrm{C}$ is almost constant with a figure lower than $0.5 \%$ for all applied stress levels whilst for tests I it increases gradually up to $2.8 \%$ for $350 \mathrm{MPa}$. In the case of tests II, the transformation strain $\left(\varepsilon_{\mathrm{M}}\right) 10{ }^{\circ} \mathrm{C}$ stabilizes at about $6 \%$ when the stress exceeds $150 \mathrm{MPa}$, whilst this saturation is not clear during tests I. During tests II a work-hardening process due to the overlap of SATWME cycles on the same sample is present. This procedure accumulates a true plastic strain after each cycle related to the introduction of defects, chiefly dislocations, into the material, similarly to the effect of the marforming and ausforming treatments defined by Treppmann and Hornbogen ${ }^{17}$. These defects can reduce the mobility of the martensite interfaces during cooling explaining the smallest values of $\left(\varepsilon_{M}\right)_{10}{ }^{\circ} \mathrm{C}$ in tests II. For the same reason, SATWME is reduced for stresses higher than $150 \mathrm{MPa}$ in tests II compared to tests I in Fig. 4(b). The difference between the SATWME for the two tests can reach $1 \%$ for $350 \mathrm{MPa}$. However, the saturation of SATWME after $150 \mathrm{MPa}$ indicates a maximum orientation of martensite variants by the applied stress during the two tests. This maximum orientation of martensite variants for $150 \mathrm{MPa}$ can also be verified on the end of the plateau stress

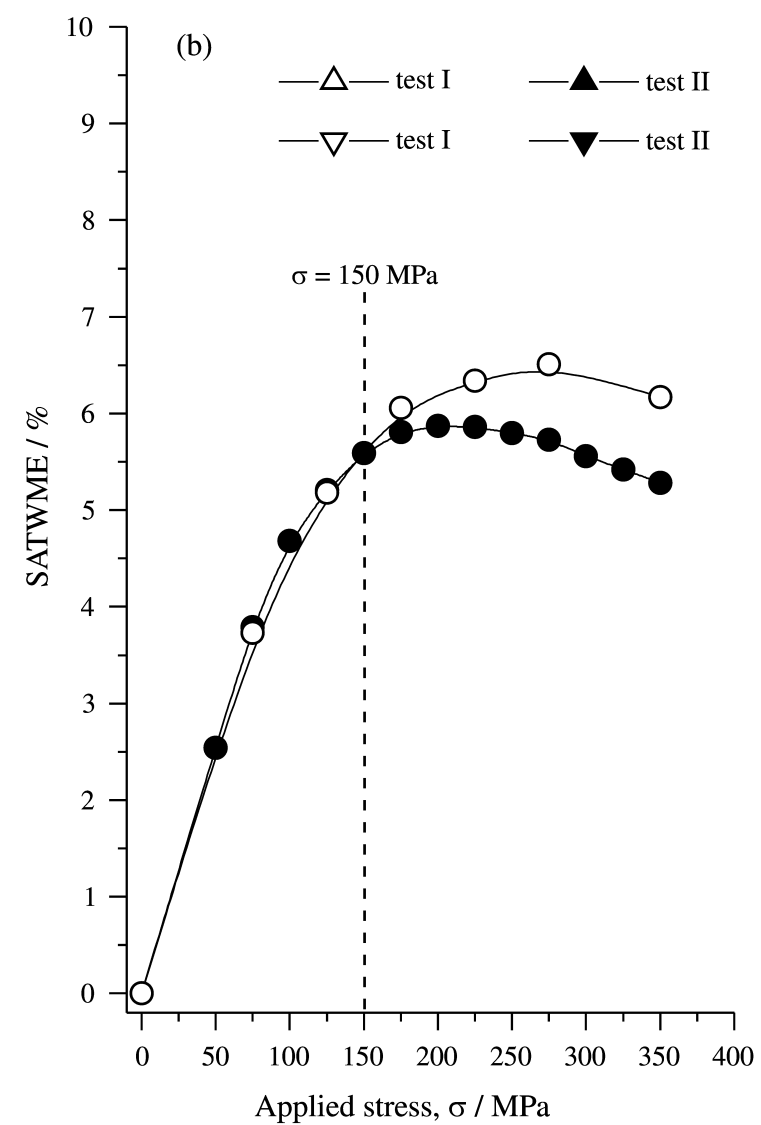

Figure 4. Strains as a function of the applied stress for tests I (open symbols) and II (solid symbols). (a) Transformation strain $\left(\varepsilon_{\mathrm{M}}\right) 10^{\circ} \mathrm{C}$ and plastic strain ( $\varepsilon$ P) $154^{\circ} \mathrm{C}$. (b) SATWME. 

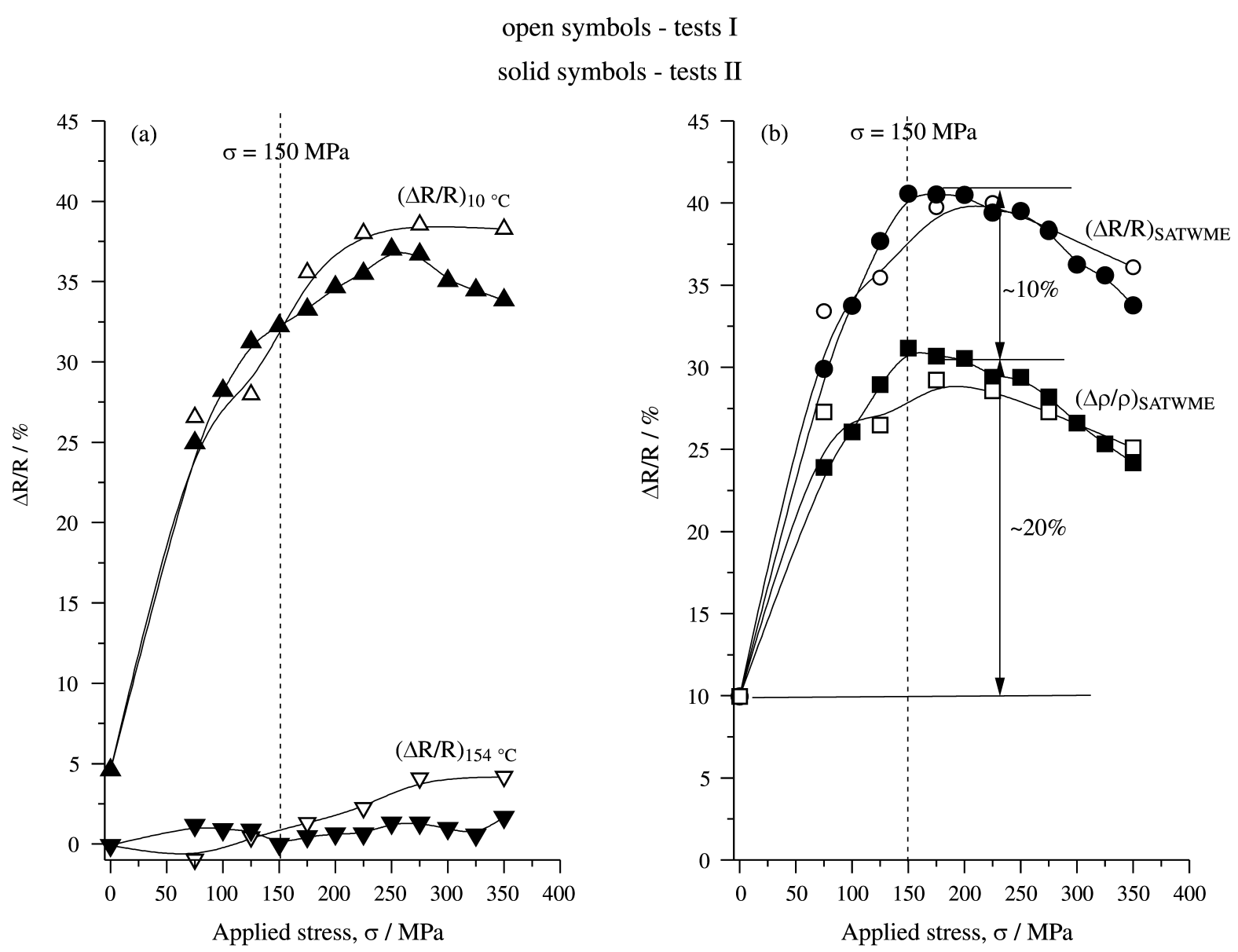

Figure 5. Normalized variation of ER associated to the strains shown in Fig. 4: (a) $(\Delta R / R) 10^{\circ} \mathrm{C}$ and $(\Delta R / R) 154^{\circ} \mathrm{C}$ associated to $\left(\varepsilon_{M}\right) 10^{\circ} \mathrm{C}$ and $(\varepsilon P) 154^{\circ} \mathrm{C}$; (b) $(\Delta \mathrm{R} / \mathrm{R})$ SATWMEand $(\Delta \rho / \rho)$ SATWMEassociated to SATWME.

observed during the uniaxial tensile test of the HT specimens in the martensitic state, as pointed out in Fig. 2.

\subsection{Variation of ER}

Figure 5 shows $\Delta R / R$ as a function of the applied stress measured concomitantly with the strains plotted in Fig. 4, during the two tests.

Qualitatively, comparing Figs. 4(a) and 5(a), it can be seen that these properties follow the same global behavior, i.e., the ER change increases steeply bellow $150 \mathrm{MPa}$ and slowly later, similarly to the strain evolutions. On the other hand, Figs. 4(a) and 5(a) also reveal that differences between the two tests concerning the behavior of the $\left(\varepsilon_{\mathrm{M}}\right) 10^{\circ} \mathrm{C}$ and $\left(\varepsilon_{\mathrm{P}}\right)_{154}{ }^{\circ} \mathrm{C}$ strains (Fig. 4a) have a minor effect on $(\Delta R / R)_{10}{ }^{\circ} \mathrm{C}$ and $(\Delta R / R) 154^{\circ} \mathrm{C}$. This is also the case for the ER properties linked to the SATWME, as shown in Fig. 5(b). Therefore, the differences in the measured strains during tests I and II (Fig. 4) are not responsible for big differences in the ER (Fig. 5). So, considering tests I and II, results in Fig. 5 support that orientation of martensite variants contribute to the major ER change in comparison with dimensional changes. Figure 5(b) also show the vari- ation of electrical resistivity associated to the SATWME, $(\Delta \rho / \rho)_{\text {SATWME, }}$ obtained by applying Eq. (3). For the stress corresponding to the maximum orientation of martensite variants, $150 \mathrm{MPa}$, Fig. 5(b) indicates that the contribution due to orientation of the variants by the applied stress is two times higher than the one due to the dimensional change of the specimen (SATWME). This observation was recently used by De Araújo et al. ${ }^{18}$ to explain the ER behavior in terms of internal stresses created in $\mathrm{Ti}-\mathrm{Ni}-\mathrm{Cu}$ wires broken by thermal cycling under constant load.

\subsection{Transformation temperatures}

Transformation temperatures are measured from the strain plotted in Fig. 3. The temperatures corresponding to the forward $\left(\mathrm{M}_{\mathrm{S}}\right.$ and $\left.\mathrm{M}_{\mathrm{f}}\right)$ and reverse $\left(\mathrm{A}_{\mathrm{S}}\right.$ and $\left.\mathrm{A}_{\mathrm{f}}\right)$ transformation for tests I and II, as measured from the strain loops, are plotted in Fig. 6.

A linear relationship between stress and transformation temperatures is verified on the two tests, though a change in the slope of the $\mathrm{M}_{\mathrm{S}}$ and $\mathrm{M}_{\mathrm{f}}$ temperatures is clearly observed for tests II and for stresses higher than $150 \mathrm{MPa}$. For example, the slope I of the $\mathrm{M}_{\mathrm{S}}$ temperature is about 

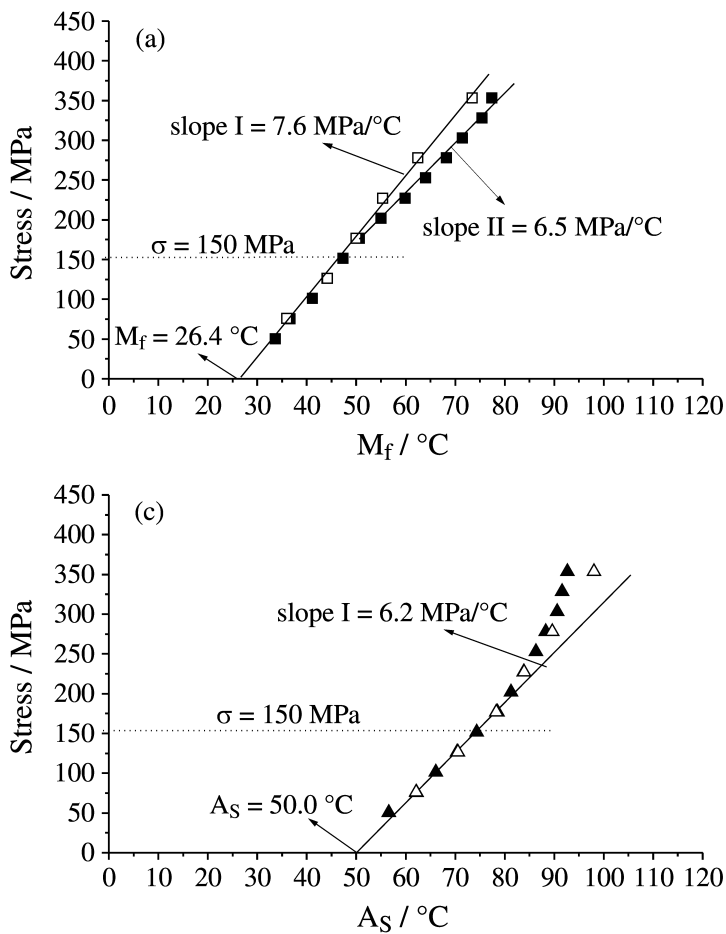
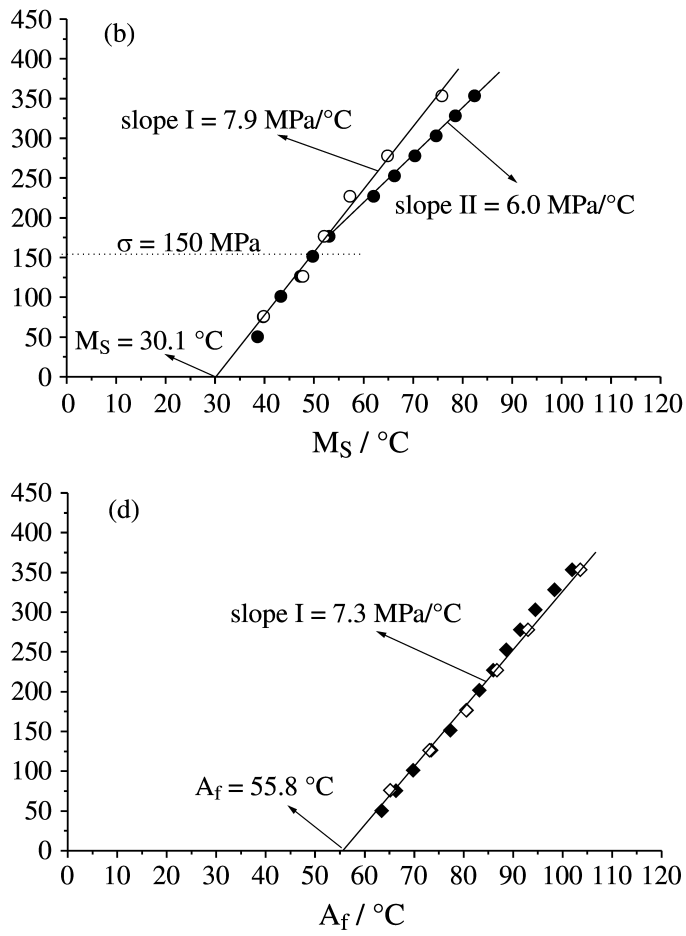

Figure 6. Transformation temperatures measured from the strain loops during tests I and II. (a) $M_{f}$. (b) Ms. (c) As. (d) Af.

$8 \mathrm{MPa} /{ }^{\circ} \mathrm{C}$ between 50 and $350 \mathrm{MPa}$ whilst the slope II has this same value below $150 \mathrm{MPa}$ and modifies to $6 \mathrm{MPa} /{ }^{\circ} \mathrm{C}$ for higher stresses. Despite tests II involve the accumulation of true plastic strain, $\mathrm{A}_{\mathrm{S}}$ and $\mathrm{A}_{\mathrm{f}}$ are practically insensitive to this fact (see Figs. $6 \mathrm{c}$ and $6 \mathrm{~d}$ ). The temperatures under stress free conditions can be obtained by extrapolation of the linear relationships as shown in Fig. 6. Comparing the extrapolated temperatures from Fig. 6 with the ones shown in Fig. 1 allows us to note some differences which are larger (about $7{ }^{\circ} \mathrm{C}$ and/or $8{ }^{\circ} \mathrm{C}$ ) for the forward transformation $\left(\mathrm{M}_{\mathrm{S}}\right.$ and $\mathrm{M}_{\mathrm{f}}$ ). The linear relationships (slopes) and transformation temperatures obtained from Fig. 6 can be used to estimate the heat of the transformation employing the modified Clausius-Clayperon law for SMA's. This modified law for SMA's is expressed by the following equation ${ }^{1}$ :

$$
\frac{d \sigma}{d T_{0}}=\frac{\Delta H^{A \rightarrow M} \cdot \rho}{T_{0} \cdot \varepsilon_{t r}}
$$

where $\frac{d \sigma}{d T_{0}}$ is the slope for the equilibrium temperature $T_{0}$ (defined as the average between $\mathrm{M}_{\mathrm{S}}$ and $\left.\mathrm{A}_{\mathrm{f}}\right)^{19}, \Delta H^{A \rightarrow M}$ is the heat of the forward transformation (austenite to martensite), $\rho$ is the specific mass of the SMA and $\varepsilon_{t r}$ is the transformation strain associated to the maximum orientation of martensite variants (Fig. 4). The slope $\frac{d \sigma}{d T_{0}}$ calculated from the data shown in Figs. 6(b) and 6(d) was
$7.8 \mathrm{MPa} /{ }^{\circ} \mathrm{C}, \varepsilon_{t r}$ from Fig. 4 is about $6 \%$ and the $T_{0}$ temperature also calculated from Figs. 6(b) and 6(d) is 316 K. Thus, applying Eq. (4) using the above calculated parameters and the specific mass of Ti-Ni based SMA's ${ }^{2}$ $\left(\rho \sim 6.45 \mathrm{~g} / \mathrm{cm}^{3}\right)$ gives $\Delta H^{A \rightarrow M} \sim 23 \mathrm{~J} / \mathrm{g}$. This value is in agreement with the one measured by DSC $\left(\Delta H^{A \rightarrow M} \sim 24 \mathrm{~J} / \mathrm{g}\right)$.

\subsection{Thermal hysteresis and true plastic strain after tests} II

It has been previously shown that strains and temperatures are affected by the mechanical history imposed by tests II in comparison with tests I. Additionally, Fig. 7(a) shows the influence of the accumulation of a true plastic strain during tests II, plotted in Fig. 7(b), on another important thermal property, the thermal hysteresis $\left(\mathrm{H}_{\mathrm{T}}\right)$, evaluated at $50 \%$ of the martensitic transformation, as indicated in Fig. 3(a).

It can be seen in Fig. 7(a), a good agreement below $150 \mathrm{MPa}$, between the $\mathrm{H}_{\mathrm{T}}$ values measured during tests I and II, similar to the results obtained for strain and transformation temperatures (Figs. 4 and 6). However, beyond $150 \mathrm{MPa}$, thermal hysteresis measured during tests II becomes lower than the ones obtained from tests I, tending to the same value measured under stress free conditions. This reduction of $\mathrm{H}_{\mathrm{T}}$ is in accord with the behavior of the transformation temperatures shown in Fig. 6 and confirm that the accumulation of a true plastic strain, plotted in Fig. 7(b), assist the forward transformation but has a minor 

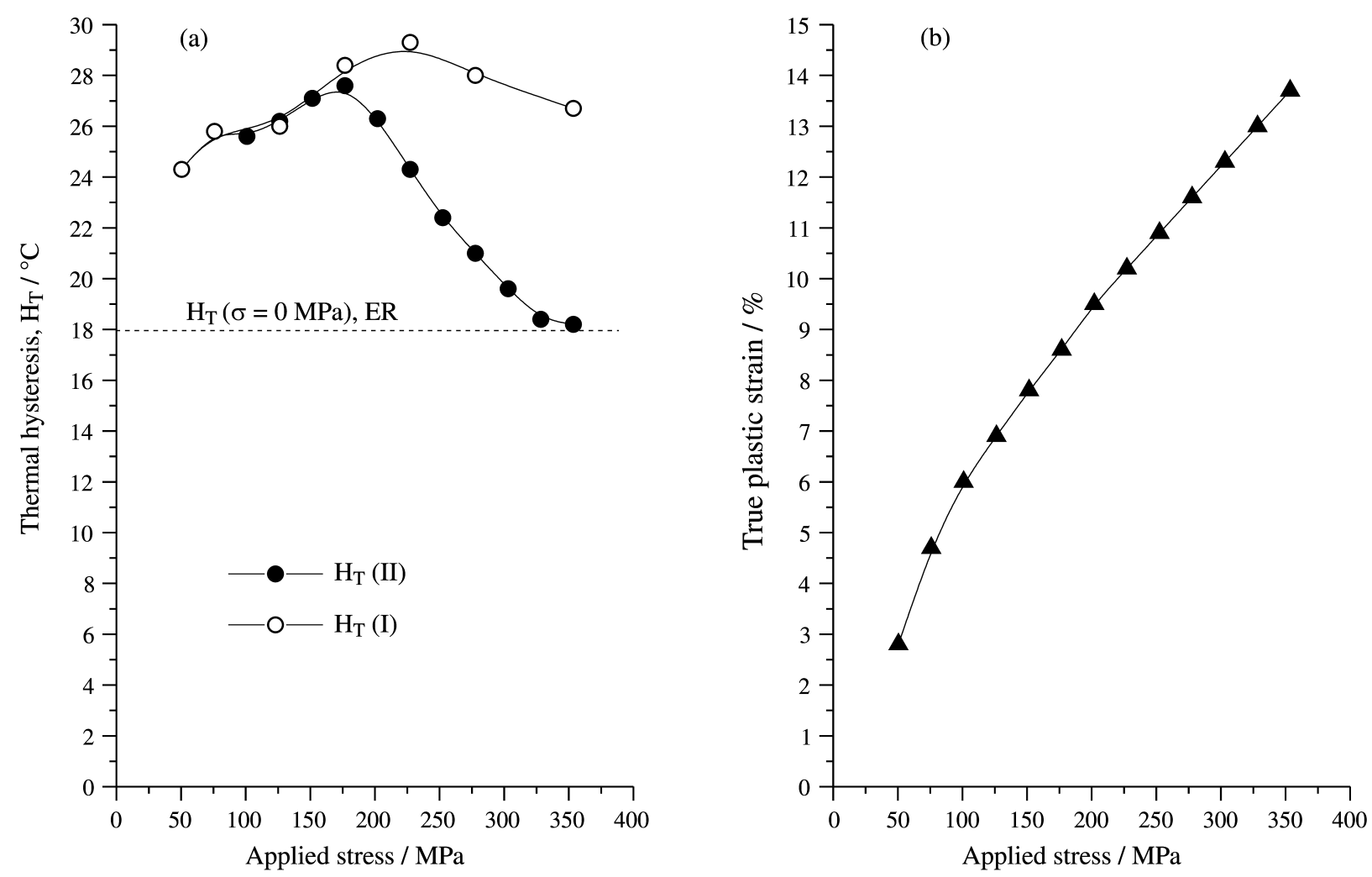

Figure 7. (a) Thermal hysteresis ( $\left.\mathrm{H}_{\mathrm{T}}\right)$ during tests I and II. (b) accumulation of plastic strain after each thermomechanical loading during tests II.

influence on the reverse transformation. This phenomenon is similar to the one observed during repeated thermal cycling under constant load for the same alloy in the stress range here studied ${ }^{20}$.

The effect of the introduction of a true plastic strain associated to tests II (Fig.7b) on the strains, variation of ER and thermal properties has been demonstrated by Figs. 4, 5,6 and 7. In fact, this plastic strain is linked to a density of defects (mainly dislocations) which should be well oriented by the applied uniaxial tensile stress. Many researchers in the field of the SMA's and more recently Nomura et $a l .{ }^{21}$ have demonstrated that these defects related to the plastic strain are at the origin of internal stresses. Considering this observation and supposing that internal stresses act as applied stresses ${ }^{22}$, De Araújo et al. ${ }^{23}$ has proposed a simple macromechanical approach to estimate internal stresses based on the evolution of the $\mathrm{M}_{\mathrm{S}}$ temperature in shape memory wires during thermal cycling under constant load. So, the deviation in the characteristic slope of the $\mathrm{M}_{\mathrm{S}}$ temperature as well as the reduction of thermal hysteresis observed during tests II (Fig. 6b and Fig. 7a) are attributed to the accumulation of plastic strain which cause an increase in the internal stress field into the material during tests II in comparison with tests I. In addition, as shown in Figs. 4(b), 5(a), 6(a) e 7(a), these deviations appear when the applied stress exceeds a critical stress level corresponding to $150 \mathrm{MPa}$.

\section{Conclusions}

This study has clearly shown that the characterization of the thermomechanical properties of SMA's using only one sample by overlapping it with growing constant loads affect some important properties as the SATWME, the transformation temperatures and the thermal hysteresis. This effect becomes important when a critical stress level corresponding to the end of the plateau stress in martensitic state (150 MPa in this case) is exceeded. This behavior is attributed to the accumulation of a true plastic strain that raises the internal stress field into the material during tests. However, variation of electrical resistivity associated to the formation and reversion of oriented martensite variants, $(\Delta R / R)_{\text {SATWME }}$ and $(\Delta \rho / \rho)_{\text {SATWME, }}$ are practically unaffected by this accumulation of plastic strain indicating that defects, mainly dislocations, give a negligible contribution to the ER change compared to the large contribution related to oriented martensite variants.

\section{Acknowledgements}

Gratitude is expressed to Prof. Jan Van Humbeeck (Katholieke University of Leuven - Belgium) and Prof. Etienne Patoor (University of Metz - France) for helpful discussions and to Capes Brazilian Foundation for its financial support. 


\section{References}

1. Funakubo, H. Shape Memory Alloys, Gordon and Breach Publishers, London, 273 p, 1987.

2. Wayman, C.M.; Otsuka, K. Shape Memory Materials, Cambridge University Press, Cambridge, 1998.

3. Moberly, W.J.; Melton, K.N. Engineering Aspects of Shape Memory Alloys. Duerig, T.W., ed., Butterworth-Heinemann, London, p. 46-57, 1990.

4. Nam, T.H.; Saburi, T.; Shimizu, K. Materials Transactions, JIM, v. 31, n. 11, p. 959-967, 1990.

5. Otsuka, K. Engineering Aspects of Shape Memory Alloys. Duerig, T.W., ed., Butterworth-Heinemann, London, p. 36-45, 1990.

6. Jean, R-D.; Duh, J-B. Scripta Metallurgica et Materialia, v. 32, n. 6, p. 885-890, 1995.

7. Miyazaki, S.; Igo, Y.; Otsuka, K. Acta Metall., v. 34, n. 10, p. 2045-2051, 1986.

8. Lin, H.C.; Wu, S.K.; Chou, T.S.; Kao, H.P. Acta Metall. Mater., v. 39, n. 9, p. 2069-2080, 1991.

9. Hornbogen, E.; Kobus, E. Z. Metallkd., v. 87, n. 6, p. 442-447, 1996.

10. Hornbogen, E. Z. Metallkd., v. 86, n. 10, p.656-664, 1995.

11. Lin, H.C.; Wu, S.K. Metallurgical Transactions A, v. 24A, p. 293-299, 1993.
12. Lin, H.C.; Wu, S.K. Acta Metall. Mater., v. 42, n. 5, p. 1623-1630, 1994.

13. Liu, Y. Shape Memory Behaviour, Ph.D. Thesis: University of Western Australia, Nedlands, Australia, 252 p., 1990.

14. Ishida, A.; Sato, M.; Takei, A.; Miyazaki, S. Materials Transactions, JIM, v. 36, n. 11, p. 1349-1355, 1995.

15. De Araújo, C.J.; Morin, M.; Guénin, G. Journal de Physique IV, v. 7, n. 11, p. 501-506, 1997.

16. Airoldi, G.; Ranucci, T.; Riva, G.; Sciacca, A. J. Phys.: Condens. Matter, v. 7, p. 3709-3720, 1995.

17. Treppmann, D.; Hornbogen, E. Journal de Physique $I V$, v. 7, n. 11, p. 211-220, 1997.

18. De Araújo, C.J.; Morin, M.; Guénin, G. Journal de Physique $I V$, in press.

19. Ortin, J.; Planes, A. Acta Metall., v. 36, n. 8, p. 1873-1889, 1988.

20. De Araújo, C.J. PhD Thesis: INSA de Lyon, Villeurbanne, France, 177 p., 1999.

21. Nomura, K.; Miyazaki, S.; Ishida, A. Journal de Physique IV, v. 5, p. 695-699, 1995.

22. Patoor, E.; Barbe, P.; Eberhardt, A.; Berveiller, M. Journal de Physique IV, v. 1, n. 11, p. 95-100, 1991.

23. De Araújo, C.J.; Morin, M.; Guénin, G. Journal of Intelligent Materials Systems and Structures, v. 11, p. 516-524, 2000. 